\title{
Response To Intervention For Young Children With Mild, Moderate/Severe Cognitive Disabilities: Literature Review
}

Nabil Almalki, King Saud University, Saudi Arabia

Abdulrahman Abaoud, King Saud University, Saudi Arabia

\begin{abstract}
This study has discussed in-depth information about understanding the Response to Intervention (RTI) linking with children from pre-school to kindergarten (three to eight years old) who have Cognitive Disabilities (CD), including different levels from mild to moderate and/or severe. The study consists of five main sections - RTI, CD, RTI Linking with CD, teaching methods for children with $C D$, and how RTI helps disability in school. Each section is presented in comprehensive detail.
\end{abstract}

Keywords: Response To Intervention; Cognitive Disability; Young Children

\section{INTRODUCTION}

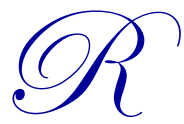

TI is an organized practice that includes all learners in education "for prevention, advancement, and early intervention, which involves determining whether all students are learning and progressing optimally academically, socially, emotionally, and behaviorally when provided with high quality instruction that addresses all aspects of students" (Indiana Department of Education [IDOE], 2009, p. 6). In addition, the 2010 definition of RTI from the IDOE is a planned process to serve students with needs through professional responsibility to ensure that educators identify and support individual students, and there is continuous monitoring of student data to estimate the success of teaching and the distribution of scientific, research-based core curriculum and education.

RTI has three important levels or tiers, which are core curriculum instruction, target instruction, and intensive instruction. Each of these tiers helps all students from kindergarten through high school, including those with disabilities, to acquire the many skills that they will need throughout their lives (IDOE, 2010). According to 511 IAC 7-41-3 of Article 7 (2010), Sec. 3, "A cognitive disability is manifested during the developmental period, is characterized by significant limitations in cognitive functioning, is demonstrated through limitations in adaptive behavior, and adversely affects educational performance" (p. 68).

The purpose of this present study is to find the appropriate information about children with CD and to know how RTI can help this population. The study focused on mild and moderate CD because, as is known, children with severe disabilities need much support, like one-on-one instruction and individualized curricula that help them successfully focus on their tasks. The importance of RTI in the field of special education is obvious, so it is vital that children with disabilities have RTI services and support that enhance the quality of education throughout their lifespans. 


\section{RESPONSE TO INTERVENTION}

According to the National Association of State Directors of Special Education and the Council of Administrators of Special Education (2006), RTI provides high quality education, including instruction and intervention, that meets the students' needs and implements learning rates with them in order to know what levels of performance they have. In addition, RTI is the general education problem-solving practice used in order to evaluate students and make educational decisions to give support to all students who experience difficulties at school.

Hoover (2010) mentioned that RTI should reduce referrals and placements into special education classrooms and help to enhance decision-making in special education. This means trying to identify the strengths of students and give them as much support as they need that is possible in the general education classroom. Another study, by Bender and Shores (2007), found that RTI approach reduced the special education placements within grades $\mathrm{K}$ to three by providing early intervention and instruction services for all students who need support at a specific level.

Hazelkorn, Bucholz, Goodman, Duffy, and Brady (2011) reviewed 128 journal articles about RTI in order to know the implementation of the RTI model for general educators and who is responsible for using the RTI practices in schools. Moreover, they concluded that RTI usually focused more on teachers of students with special needs than on other teachers. They mentioned the important point that the collaboration among state, the Local Education Agency (LEA), and all professionals will help to effectively implement RTI in schools.

Hoover and Love (2011) pointed out that three schools in the western United States implemented the RTI model effectively. They further mentioned several key elements to successfully using the RTI model in school: 1) Three tiers of intervention for all students, with those placed in tiers in regard to their abilities and needs, 2) using qualified data, which includes screening, monitoring, and diagnostic assessment, and 3) evidence-based practice. It is important to note most students are placed within tiers one and two, so both those tiers are considered essential for success for any RTI approach.

O'Connor and Sanchez (2011) mentioned the important point that academic or behavioral interventions through RTI models are planned to reach the highest level of a child's ability. In addition, RTI was originally designed to enhance the performance of students at-risk for Learning Disability (LD), both in reading and in mathematics skills. The authors also pointed out that tier two of the RTI model is very important, especially in eligibility decisions for special education placements. All kinds of needs and wants for students must be considered in order to give them the appropriate intervention they need. RTI in Indiana contributes to using systemic changes of implementing the RTI model and the IDOE (2009) mentioned six critical components of the RTI approach: 1) "leadership; 2) cultural responsivity; 3) family, school, and community partnerships; 4) evidence-based core curriculum, instruction, and interventions/extensions; 5) data-based decision-making, assessment and progress monitoring system, and 6) assessment and progress monitoring system" (p. 17). These components play a significant role in implementing the RTI model effectively within schools and help all students achieve academic, social, communication, and behavioral skills.

Fuchs, Fuchs, and Stecker (2010) included in their article a great deal of information about two groups of the No Child Left Behind (NCLB) and Individuals with Disabilities Education Act (IDEA) (2004) that leads to understanding the framework for the RTI model. They also pointed out that RTI would enhance early intervention and the method of disability identification for students with disabilities. In addition, the NCLB group focuses on the standards setting that has determined public education improvement and emphasizes the assessments for all students, including individuals with disabilities, and school level accountability with concern about students' performance.

\section{COGNITIVE DISABILITY}

According to Polloway, Patton, and Nelson (2011), the development of preschool programs depends on the degree of intervention and identification for individuals with intellectual disability or CD. Part B of the IDEA mandated that all children aged three to five have the right to free appropriate public education (FAEP). They also mentioned the percentage of placements of children with $\mathrm{CD}$ in schools - 82\% of them are placed in separate 
classrooms around $21 \%$ of the school day and $56 \%$ of them were removed from general classrooms at least $60 \%$ of the day, which means these children are taught in separate classrooms. It is important for all students with disabilities, including mild ones, to get the educational needs they want. According to Vallecorsa, Debettencourt, and Zigmond (2000), all educational needs for those students with mild disabilities could be met in the general education classroom by providing accommodations and modifications for them. In addition, general and special education teachers should work together in order to use the appropriate strategies in the classrooms.

The World Health Organization (WHO) mentioned that most young children with intellectual disabilities are provided special education facilities, even though they get educational services in mainstream or local educational agencies. This is based on integration within each school district. Shulman, Flores, Iarocci, and Burack (2011) pointed out the importance of inclusion for students with intellectual disabilities beside their normal peers. Children with intellectual disabilities benefit from inclusion with their peers without disabilities by the enhancing of their functional and academic skills, as well as social and communication skills.

The IDEA (2004) and NCLB (2001) encourage school districts to help all students, including individuals with disabilities, by improving reading, math, science, and other academic instruction for these students. It is significant that each teacher be well prepared to deal with all students with disabilities, including those with CD. To that goal, the IDEA (2004) requires training of individuals who give services to children with disabilities and to limited English skilled children. Moreover, "SEC. 654 of the IDEA (2004) mentions the important point of providing effective instruction for children with low incidence at school" (p. 125). This means to help this population to the greatest extent of appropriate services possible.

The NCLB (2001) also helps all students from three to 21, including students with disabilities, to get special and related services, and it aims "To close the achievement gap with accountability, flexibility, and choice, so that no child is left behind" (p. 1425). This means providing equal opportunities for all students to learn and to achieve the services they need at school. In fact, all children with disabilities, especially those with CD, benefit from these laws and regulations to enhance their performance across their lifespans. In the next section, the RTI model and $\mathrm{CD}$ will be discussed with focus on the best evidence practices.

\section{RESPONSE TO INTERVENTION LINKING WITH COGNITIVE DISABILITY}

RTI was originally designed for students with learning disabilities (LDs). However, it also assists some children with special needs, such as those with CD, who face difficulties at schools (IDEA, 2004). According to Grigorenko (2008), all children who remain in the intensive tier after receiving two diagnostic tutorial cycles are classified as LD in reading. These students will be given additional evaluations, which consider other disabilities, such as mental retardation (MR), attention-deficit/hyperactivity disorder (ADHD), and communication disorder (CD). For that, students with special needs should, to the greatest extent possible, be provided the accommodations and modifications that help them to be successful in school classes.

A recent study conducted by Kavale and Spaulding (2008) indicated the difficulty of classification among Mild Disabilities (MD) and Specific Learning Disabilities (SLD). Using RTI as the lone criterion of identity develops problems to "1) distinguish SLD from mild MR, 2) distinguish students with SLD from SL, 3) identify intra-individual differences, 4) determine the meaning of a positive RTI, and 5) identify the best means to implement intervention activities" (p. 175). Diagnosis has to provide a comprehensive assessment or evaluation in order to identify the disability and then meet all special and related services needed throughout their lifespans for individuals with disabilities, both MD and LD.

Because the RTI model is frequently used in general education classrooms for all students, the Universal Design for Learning (UDL) really helps students with CD, including mild disabilities, to have access to general classrooms. Wehmeyer (2006) mentioned the importance of UDL in helping those students to benefit from general classrooms by providing appropriate curricula and supplementary aids for them in order to learn effectively at schools. From the important study conducted by Musti-Rao, Hawkins, and Tan (2011), not only does RTI help to identify students with LD, but it also helps to provide a framework for general education teachers for problemsolving at the classroom level. According to Cote (2011), children with mild to moderate disabilities have a deficit 
in problem-solving, so they need intervention that helps them in this situation. The instruction for problem-solving has several benefits for these students. For instance, they can profit from instruction that encourages autonomous problem-solving and teaches further skills that could be used throughout the students' lives, and the students can understand their abilities to impact the outcomes of problems by the choices they make.

\section{TEACHING METHODS FOR CHILDREN WITH COGNITIVE DISABILITY}

Children with mild disabilities or CD need assistance to connect academic learning to real-life experiences and adjust how to approach learning activities (Henley, Ramsey, \& Algozzine, 2006). Henley at al. indicated some effective teaching and general procedures that lead to improvement of instruction, thinking skills, teaching reading, school adaptive behavior, leisure, and work skills or daily living. They further mentioned that special education teachers should use the intervention model with children with mild CD in order to teach them effectively at school. It is important for each teacher, special or general education, to consider the appropriate teaching model for these children with $\mathrm{CD}$ in order to help them gain skills such as reading, math, language arts, and science.

According to Cooper-Duffy, Szedia, and Hyer (2010), teachers use effective methods to teach children with CD with linking to Standards Course of Study (SCOS) with Individual Education Plan (IEP) for them. This article described Albert as a second grade child with cerebral palsy, seizures, and significant CD, and Sweeny is this child's teacher. She mentioned that time delay was a very effective method for teaching sight words and other academic skills to children with significant $\mathrm{CD}$. In addition, special education teachers face difficulties in teaching children with CD linking to SCOS and deciding what instructional approach should be used.

Passe and Beattie (1994) conducted a study about teaching social studies to children with mild disabilities or CD in public education classrooms. They indicated that general education teachers are responsible for offering academic instruction for children with mild disabilities during the majority of the school day. Meeting the needs of these children makes instruction in social studies in the classroom very challenging because the children might have limited reading skills. In fact, a survey was used to evaluate the specific social studies instructional methods, and around 197 surveys were sent to teachers in five different school districts. Of the total, 142 responded and 17 gave additional data by doing interviews. The results indicated that the most effective adaptations for social studies were peer tutoring, special seating assignments, different reading materials, ability grouping, different tests, and audiovisual supports. In general, successful achievement is limited even though teachers reported support for children with mild disabilities or CD.

Browder and Spooner (2006) highlighted an important point for teaching math skills to children with mild $\mathrm{CD}$ or high incidence disabilities. They mentioned the direct instruction or approach as a very effective method for teaching the basic facts of math to these children. Self-instruction methods promote problem-solving for children with mild disabilities. Because these children face difficulty with mathematics curriculum reform, especially because of the challenges with distinction and processing of related information, the deficit in the capacity calculations, and inefficiency in thinking and problem-solving skills, they need support and modification in general education classrooms in order to acquire skills they will need throughout their lifespans. It is important to implement assistive technology for teaching and assessment in the math instruction for those children with mild disabilities or CD.

Henley et al. (2006) highlighted the important instructional methods or models used to teach children with mild disabilities or $\mathrm{CD}$ as well as children without disabilities. It is important to indicate some of these methods in brief. The first teaching model is direct instruction, which refers to "a variety of carefully sequenced, teacherdirected methods" (p. 255). They should include a teacher demonstration, guided practice, and feedback. The second teaching method is multisensory, which is based on "the premise that the more senses involved, the more efficient the instruction" (p. 257). In fact, many children with mild disabilities or CD have severe reading problems, so this approach helps them by providing reading programs that assist them in those reading skills at school. The third teaching method is task analysis, which refers to "the process of breaking a learning task down into its component parts and teaching each part as a distinct skill" (p. 258). The fourth teaching method for children with mild disabilities or $\mathrm{CD}$ is precision teaching, which means learning could be enhanced by frequent, self-recorded responses on the standards charts. This actually encourages teachers to focus on the rate of responses instead of focusing on percentages of correct responses. 
Two important studies indicated different teaching methods used with children with CD. Spooner, Rivera, Browder, Baker, and Salas (2009) did a study which included teaching emergent literary skills using cultural contextual story-based lessons for the child who was an English-language learner with moderate intellectual disabilities or CD. They found that this method led to an increase in emergent literacy skills for this child. Another study, conducted by Joseph and McCachran (2003), did a comparison of a world study phonics technique on "word recognition, pseudoword recognition, phonological awareness, and spelling" between young children with moderate to mild mental retardation or $\mathrm{CD}$ and young children who were struggling with reading skills but did not have disabilities. They found no statistically important differences among the groups upon post-test events of "word recognition, pseudoword recognition, phonological awareness, and spelling while holding pre-test performance on these variables constant. There was variability in performance within groups, especially within the group of children with mental retardation" (p. 192).

\section{HOW THE RESPONSE TO INTERVENTION HELPS DISABILITY IN SCHOOL}

As was mentioned earlier, RTI tries to avoid referring students to special education classrooms or placements, so Tier 3 of the RTI model represents special education. According to Grigorenko (2008), the students with mild disabilities or CD sometimes place in Tier 3 after evaluations are made in order to determine the nature of the disability and distinguish between other kinds of disabilities, such as emotional disorder (ED) and LD. This assessment, a multidisciplinary evaluation, was made in order to assign students to appropriate placements and classrooms from whose many services they will benefit.

As was stated in Kauffman and Hallahan (cited in Wissick and Gardner (2011) wrote that RTI was designed to meet all students' needs by creating appropriate curricula and effective instruction. It also has to align with the concept of incorporating evidence-based practice and with the process of monitoring for early intervention. In classrooms, differentiated instruction should be implemented for all students. Therefore, Assistive Technology (AT), UDL, and RTI should be used by special and general education teachers together in order to help all students who need assistance and support. This means that all these concepts help all students when implemented together and effectively. For clarification, the use of universal interventions should be selected for students who need access to general education classrooms.

RTI will help students in the school by providing differentiated instruction. Henley et al. (2006) pointed out that the importance of these methods is to make adaptations from which the students benefit. Moreover, Henley et al. actually mentioned that modifications would be in content, process, product, and resources. Teachers should assess the students' needs and abilities in several ways, such as observation and student conferences. In this way, teachers will know more about the students' abilities and needs when they use different approaches, and can then provide appropriate instructions and effective teaching methods for these students.

By looking at the preschool curriculum or instruction for three- to five year olds, Jones (2000) mentioned different curricula used with young children, which are the activity and subject curricula which includes the integrated curriculum. The activity curriculum focused on many activities with no attempt to teach reading and math skills, while the subject curriculum focused on many skills, such as math, reading, science, social studies, language arts, and health and safety. In fact, "academic curriculum for students with mild disabilities is based on the state-adopted general education curriculum and state-adopted minimum competencies. Also, specialized curricula frequently associated with students with mental retardation include developmental skills and essential life skills" (p. 19).

Young children with mild CD, or even moderate disabilities, could benefit from the RTI model by using differentiated instruction and special education services in Tier 3. This was supported by the National Association of State Directors of Special Education (NASDSE) when it was mentioned in one of its resources - NASDSE and the Council of Administrators of Special Education (CASE) White Paper on RTI - that "we can effectively teach all children" (2006, p. 3). This means that educators should encourage special and general education teachers to use the methods that are appropriate for young children with mild CD, including English-language learners, in order to provide the assistance they will need throughout their lives. 
It is necessary to mention that UDL plays a critical role in teaching children with disabilities, including those with mild CD. It provides an effective curriculum that gives all children equal opportunities to learn in appropriate environments. As mentioned by the Center for Applied Special Technology (CAST, 2012), "individuals bring a huge variety of skills, needs, and interests to learning", so it should know the what, how, and why of learning. In addition, UDL has three primary brain networks, which are to "present information and content in different ways, differentiate the ways that students can express what they know, and stimulate interest and motivation for learning." This means that, as teachers, it should consider the needs and interests of young children with disabilities, including those with mild CD, in order to provide suitable learning environments.

\section{CONCLUSION}

The article presented comprehensive information about the RTI model that was used frequently for all children, including those who have disabilities or are at risk of having a disability. The researchers studied a great deal of information about the RTI model, which is considered vital for children from all types and levels of disabilities. Based on knowledge collected for this study, the authors believe that the RTI approach has a significant impact on children with disabilities in order to help families of children with disabilities obtain accessible resources and services they need. The authors strongly advocate the importance of using effective models, such as the RTI model, for young children with disabilities. That will give the children the chance to be identified in an early stage and allow them equal opportunities to participate in future educational settings and to effectively integrate into society.

The RTI model is considered the most effective model for all children with various types and levels of disabilities. Moreover, this approach makes one to think seriously about how to apply it effectively to real practices in schools. In fact, this study has driven to think carefully about the RTI model or interventions for children in schools who are at risk of having disabilities or have disabilities. Furthermore, the schools should consider applying the appropriate and effective interventions that these children need. The study determined that teachers should have a full understanding of the RTI model, which will prepare them to carry the most useful information to schools because this will help to improve the quality of life for children with disabilities.

\section{AUTHOR INFORMATION}

Dr. Nabil Almalki is an assistant professor in the Department of Special Education at King Saud University, Riyadh, Saudi Arabia. E-mail: nalmalki@ksu.edu.sa

Dr. Abdulrahman Abaoud is an assistant professor in the Department of Special Education at King Saud University, Riyadh, Saudi Arabia. E-mail: abaoud@ksu.edu.sa

\section{REFERENCES}

1. Bender, W. N., Shores, C., \& Council for Exceptional Children, A. A. (2007). Response to intervention: A practical guide for every teacher. Thousand Oaks, CA: Corwin Press.

2. Browder, D. M., Courtade-Little, G., Wakeman, S., \& Rickelman, R. J. (2006). From sight words to emerging literacy. In Browder, D., M., \& Spooner, F. (Eds.), Teaching language arts, math, and science to students with significant cognitive disabilities (pp. 63-91). Baltimore, MD: Paul Brookes.

3. Browder, D. M., \& Spooner, F. (2006). Teaching language arts, math, and science to students with significant cognitive disabilities. Baltimore: Brookes Publishing Company.

4. Brownell, M. T., Sindelar, P. T., Kiely, M., \& Danielson, L. C. (2010). Special education teacher quality and preparation: Exposing foundations, constructing a new model. Exceptional Children, 76(3), 357-377.

5. Center for Applied Special Technology (CAST). (2012). Universal design for learning. Retrieved from http://www.cast.org/udl/index.html.

6. Cooper-Duffy, K., Szedia, P., \& Hyer, G. (2010). Teaching literacy to students with significant cognitive disabilities. TEACHING Exceptional Children, 42(3), 30-39.

7. Cote, D. L. (2011). Implementing a problem-solving intervention with students with mild to moderate disabilities. Intervention in School and Clinic, 46(5), 259-265. 
8. $\quad$ Downing, J. (2005). Teaching literacy to students with significant disabilities: Strategies for the K-12 inclusive classroom. Newbury Park, CA: Corwin Press.

9. Fuchs, D., Fuchs, L. S., \& Stecker, P. M. (2010). The "blurring" of special education in a new continuum of general education placements and services. Exceptional Children, 76(3), 301-323.

10. Greenwood, C. R., Bradfield, T., Kaminski, R., Linas, M., Carta, J. J., \& Nylander, D. (2011). The response to intervention (RTI) approach in early childhood. Focus on Exceptional Children, 43(9), 1-22.

11. Grigorenko, E. (Ed.). (2008). Educating individuals with disabilities: IDEIA 2004 and beyond. New York, NY: Springer Publishing Co.

12. Hazelkorn, M., Bucholz, J. L., Goodman, J. I., Duffy, M., \& Brady, M. P. (2011). Response to intervention: General or special education? Who is responsible? Educational Forum, 75(1), 17-25.

13. Henley, M., Ramsey, R. S., \& Algozzine, R. F. (2006). Characteristics of and strategies for teaching students with mild disabilities, $\left(5^{\text {th }}\right.$ ed). Boston: Allyn \& Bacon.

14. Hoover, J. J. (2010). Special education eligibility decision making in response to intervention models. Theory into Practice, 49(4), 289-296.

15. Hoover, J. J., \& Love, E. (2011). Supporting school-based response to intervention: A practitioner's model. Teaching Exceptional Children, 43(3), 40-48.

16. Indiana Department of Education. (2009). Indiana's vision of response to intervention: Using response to intervention (RTI) for Indiana's students.

17. Indiana Department of Education. (2010). Response to instruction (RTI): Guidance document. Retrieved from http://www.doe.in.gov/rti.

18. Indiana Department of Education, Division of Exceptional Learners. (December 2010). Special Education Rules: Title 511 Article 7 Rules 32-47.

19. Individuals with Disabilities Education Act of 2004 (IDEA). (P.L. 108-446).

20. Jones, C. J. (2000). Curriculum development for students with mild disabilities: Academic and social skills for RTI planning and inclusion IEPs. Springfield, IL: Charles C. Thomas, Publisher, Ltd.

21. Joseph, L. M., \& McCachran, M. (2003). Comparison of a word study phonics technique between students with moderate to mild mental retardation and struggling readers without disabilities. Education and Training in Developmental Disabilities, 38(2), 192-199.

22. Katims, D. S. (2000). Literacy instruction for people with mental retardation: Historical highlights and contemporary analysis. Education and Training in Mental Retardation and Developmental Disabilities, 35(1), 3-15.

23. Kavale, K. A., \& Spaulding, L. S. (2008). Is response to intervention good policy for specific learning disability? Learning Disabilities Research \& Practice (Blackwell Publishing Limited), 23(4), 169-179.

24. Kortering, L. J., McClannon, T. W., \& Braziel, P. M. (2008). Universal design for learning: A look at what algebra and biology students with and without high incidence conditions are saying. Remedial and Special Education, 29(6), 352-363.

25. Mortier, K., Hunt, P., Leroy, M., van de Putte, I., \& van Hove, G. (2010). Communities of practice in inclusive education. Educational Studies 36(3), 345-355.

26. Musti-Rao, S., Hawkins, R. O., \& Tan, C. (2011). A practitioner's guide to consultation and problem solving in inclusive settings. Teaching Exceptional Children, 44(1), 18-26.

27. National Association of State Directors of Special Education and Council of Administrators of Special Education (2006). Response to intervention (RTI) project. Retrieved from: http://www.nasdse.org/Home/tabid/36/Default.aspx.

28. No Child Left Behind Act of 2001 (NCLB). (P.L. 107-110).

29. O’Connor, R. E., \& Sanchez, V. (2011). Responsiveness to intervention models for reducing reading difficulties and identifying learning disability. In Kauffman, J. M., \& Hallahan, D. P. (Eds), Handbook of special education. (pp. 123-133). New York, NY: Routledge

30. Passe, J., \& Beattie, J. (1994). Social studies instruction for students with mild disabilities. Remedial \& Special Education, 15(4), 227.

31. Polloway, E. A., Patton, J. R., \& Nelson, M., A. (2011). Intellectual and developmental disabilities. In Kauffman, J. M., \& Hallahan, D. P. (Eds), Handbook of special education. (pp. 173-188). New York, NY: Routledge.

32. Shulman, C., Flores, H., Iarocci, G., \& Burack, J. A. (2011). Intellectual disability: Concepts, definitions, and assessment. In Howlin, P., Charman, T., \& Ghaziuddin, M. (Eds), Handbook of developmental 
disorders. (pp. 365-402). New York, NY: SAGE publications.

33. Smith, D. D, Demarco, J. F., \& Worley, M. (2009). Beyond picture books: A thematic approach to teaching literacy skills to students with disabilities. Grades 6-12. Newbury Park, CA: Corwin Press.

34. Spooner, F., Rivera, C. J., Browder, D. M., Baker, J. N., \& Salas, S. (2009). Teaching emergent literacy skills using cultural contextual story-based lessons. Research and Practice for Persons with Severe Disabilities (RPSD), 34(3-4), 102-112.

35. Universal design for learning: A guide for teachers and education professionals. (2005). Arlington, VA: Council for Exceptional Children.

36. Vaghn, S., \& Gersten, R. (2000). The underlying message in LD intervention research: Findings from research syntheses. Exceptional Children, 67(1), 99.

37. Vallecorsa, A. L., DeBettencourt, L. U., \& Zigmond, N. (2000). Students with mild disabilities in general education settings: A guide for special educators. Columbus, $\mathrm{OH}$ : Merrill.

38. Wehmeyer, M. L. (2006). Universal design for learning, access to the general education curriculum and students with mild mental retardation. Exceptionality, 14(4), 225-235.

39. What every special educator must know: The international standards for the preparation and certification of special education teachers. (2009). Council for Exceptional Children [CEC] 6 Edition, pp.51-61.

40. Wissick, C. A., \& Gardner, J. E. (2011). Technology and academic instruction considerations for students with high-incidence cognitive disabilities. In Kauffman, J. M., \& Hallahan, D. P. (Eds), Handbook of special education. (pp. 484-500). New York, NY: Routledge.

41. World Health Organization (WHO). (2007). Services for children, adolescents, and adults. In Atlas on global resources for persons with intellectual disabilities. Geneva: World Health Organization. (pp. 37-48). Retrieved from http://www.who.int/mental_health/evidence/atlas_id_2007.pdf. 